\title{
INVESTIGATION THE EFFECT OF ARABIC GUM ON THE PHYSICAL AND MECHANICAL PROPERTIES OF ORDINARY CEMENT
}

${ }^{\star}$ Mustafa K. Rustum ${ }^{1}$
Khalid M. Oweed ${ }^{2}$

1) Dep.of MaterialsEngineering Al-Mustansiriyah University, Baghdad, Iraq

2) Dep. of MaterialsEngineering, Al-Mustansiriyah University, Baghdad, Iraq

\begin{abstract}
The presented study examined the impact of Arabic gum (AG)on physical and mechanical properties related to ordinary cement mortarby cement'spartial replacement via various quantities of Arabic gum( $0.1 \%, 0.3 \%, 0.5 \%, 0.7 \%, 0.9 \%)$, the sample mortar's preparation was achieved with using 1:2 ratio of cement to sand by weight, witha $(0.5)$ water to binder ratio. The compressive strength, flexural strength,and Workability tests were carried out on these five $\operatorname{groups}\left(G_{1}, G 2, G 3, G_{4}\right.$, $\mathrm{G}_{5}$ ) in addition to a reference group $\mathrm{G}_{0}$ that not contain Arabic gum, compressive as well as flexural strength tests were achieved after curing at early and standard age 7 and 28days, respectively. The results specified that the compressivein addition to flexural strengths of samples of groups $\mathrm{G}_{1}, \mathrm{G}_{2}, \mathrm{G}_{3}$ mortars were increasing with the increase of replacement's ratio $(0.1 \%, 0.3 \%, 0.5 \%)$ and then decreased at $\mathrm{G}_{4}$ and $\mathrm{G}_{5}(0.7 \%$ and $0.9 \%)$ and The best results were recorded at $\mathrm{G}_{3}(0.5 \%$ replacement ratio) where enhancement of compressive strength $17 \%$ and $16 \%$ for early and standard age respectively and enhancement of flexural strength $11 \%$ and $10 \%$ for early standard age respectively, the results of workability test refers to that the increase of the ratio of Arabic gum (AG) in the mortar increaseits workability, from SEM analysis indicated in sample Gзwere more homogeneous microstructure in comparison to the microstructure of $\mathrm{G}_{0}$.
\end{abstract}

Keywords:Arabic gum, compressive strength, flexural strength, microstructural analysis, Workability, scanning electron microscopy (SEM).

\section{Introduction}

The Arabic Gum or the Acacia gum was considered as edible biopolymer that wasacquired as exudates related to the mature trees of Acacia seyal as well as the Acacia Senegal that principally grow in the African region of Sudan's Sahel. Chemically, Arabic Gum was defined as a complex mixture related to macromolecules with various compositions and sizes (majorly proteins and carbohydrates). The features and properties related to AG were extensively examined and developed, also being applied in a lot of industrial sectors, including food, pharmaceuticals, lithography, ceramics, textiles, cosmetics, encapsulation, food, and so on. $[1,2]$. Arabic Gum was chosen in this work as it is a biopolymer available in the local markets in Iraq and has a lower cost than other polymers.

Numerous works were conducted using Arabic gum(AG) to study its impact on the physical and mechanical properties of cement mortars.

Khayat et al. [3] Studied the influence of Arabic gum (AG) as viscosity modifying agent (VMA) on rheological properties related to water and cement paste. The VMAs were specified as polysaccharides that are enhancing the stability and cohesion of cement-based systems. Also, there is an increase in the water retention capacity, where as the bleeding and segregation characteristics were enhanced, also there is an increase in the mortar's flowability, performance, 
and homogeneity of the hardened concrete were enhanced. They were utilized together with the superplasticizers in the Self Compacting Concrete (SCC) to improve the workability and ensure the high deform-ability. Furthermore, the initial, as well as the final setting time regarding the mortar, was prolonged in the case when such admixtures are applied. The AG found some applications in the construction industry, particularly in the hot weather climates as they are prolonging concrete's plastic state, therefore allow time for transportation, placing as well as finishing.

C. Zhao et al. [4] Examined the dispersion impact related to the $A G$ and the factors impacting holding capacity related to $A G$ in the cement throughout hydration, the cement paste's rheological properties with the added AG powder. The results indicating that the $0.10-0.60$ wt\% regarding $A G$ positively impacting the dispersion, while the low dosage has an insignificant impact. The high-speed mixing was needed for maintaining the AG's dispersion stability in the cement's paste. The optimal dosage related to $\mathrm{AG}$ for achieving optimum disperse-holding capacity regarding the cement paste was $0.30 \mathrm{wt} \%$, also the minimal watercement ratio which is required for obtaining dispersion impact was 0.28.

P. Zakkaet al. [5] examined AG's suitability in terms of the capability for acting as a plasticizer in the concrete was put to test with the target of creating self-compacting concretes. Also, the fresh concrete's self-compacting properties were put to test, also the compressive strength related to concrete created. Furthermore, utilized 2 concrete mixes with various ratios of water/powder were applied. Concrete (normal) which were serving as control had a ratio of water/cement $(\mathrm{W} / \mathrm{C})=0.50$, whereas Self Compacting concrete that had AG as plasticizer at 2 distinctive percentage values had a ratio of water/powder 0.45 . The study indicated that AG was optimum plasticizer in addition to excellent viscosity modifying agent to be utilized in the inexpensive self-compacting concretes.

R. Mbugua et al. [6] examined the impact of the Gum from Acacia Karroo (GAK) as set-retarding admixtures in the cement's paste. The potential to use the GAK as water decreasing admixture in the mortar of the cement was examined. The cement pastes were prepared for measuring setting time with the use of various dosages related to GAK, were conducted through mixed. There are 500 grams regarding OPC with the GAK at $0,0.30 \%, 0.40 \%, 0.50 \%, 0.60 \%, 0.70 \%$, $0.80 \%, 0.90 \%$ and $1 \%$ wt (cement's weight). The trade CE (commercial admixture) with dosages of $0.30 \%, 0.40 \%, 0.50 \%, 0.60 \%$ as well as $0.70 \%$ wt was utilized based on manufactures instruction Control was the neat cement paste. The flow test, bleeding, and compressive strength was examined on the cement's mortars with control being the cement mortar with no admixtures. GAK was indicated for increasing the final time of the setting by six hours over control. The compressive strength is increasing with a decrease in W/C from 0.50 to 0.40 . Thermogravimetric analysis indicated an elevated dose of GAK decreased rate of hydration.

A.U. Elinwaet al.[7] examined the compressive strengths related to $\mathrm{AG}$ increased over control (M-0.00) with the increase in dosage. The maximum strength was done at a dosage of $0.50 \%$. The properties related to tobermorite, osumulite, and certain other minerals in the AG samples were considered as factors that contribute to optimal strength which is accomplished at such dose. The osumulite, defined as potassium magnesium aluminium silicate, and chemical formula $\mathrm{KMg} 2 \mathrm{Al} 3$ (Si10Al2) O30, and ahexagonal crystal structure, and tobermorite, which is a calcium silicate hydrate, represented as $\mathrm{CaSi} 6(\mathrm{O}, \mathrm{OH}) 18.5 \mathrm{H} 2 \mathrm{O}$, exist in $A G$ samples at a0.50\%dose. The 
tobermorite has mono-clinic crystal structures and it's anisotropic in the character with fairly high resistance to the external Isostatic compressions. Furthermore, minerals were comparable to $\mathrm{C}-\mathrm{S}-\mathrm{H}$ phases (Calcium Silicates Hydrates) created in the process of hydration related to Portland cement. The minerals such as Wollastonite, Mordenite, and Sepiolitewere also indicated in the samples of $\mathrm{AG}$ at the dosage of $0.50 \%$, also they affect mechanical strength as well as the physical characteristics regarding concrete. The wollastonite minerals were indicated for enhancing concrete's compressive andflexural strengths. The aims of this work

1.obtain anew cement formula in dry form can be easily prepared by partial replacement of cement by Arabic Gum (AG) in suitable ratio, the new formula has higher physical and mechanical properties than that of ordinary Portland cement.

2. Studying the effect of biopolymer (AG) in different ratios on the cement properties.

3. Detect the effect of Arabic gum(AG) on the microstructure of the new cement by using scanning electron microscopy (SEM).

\section{Materials}

\subsection{Ordinary Portland cement}

About the presented study, the cement that was used is the type1 of the Ordinary Portland Cement (OPC) that is commercially referred to as (MASS), manufactured in Al-Sulaimaniya, Iraq, stored in a dry place to protect it from atmospheric conditions.

The chemical and physical analysis were conducted via Laboratories of the University of Baghdad / Department of Engineering Affairs. The test results are specifying that the sample complies with the Iraqi specification (IQS No.5 /1984) [8].

\section{2.sand}

AL- Ukhaidher, in Karbala, Iraq, natural sand [that was used in this study that has a fineness modulus (FM) equal to 2.74, bulk specific gravity (Sp. gr.) which is equal to2.6and $(0.39 \%)$ sulfate content (SO3\%) by the sand weight, which conforms with IQS limit No.45 / 1984[9]. in the present study, only sand $<(4.75 \mathrm{~mm})$ was utilized for the achievement of mixing characteristics and requirements.

\subsection{ArabicGum (AG)}

Typical properties of Arabic gum (AG) given in table1[10].

Table 1. Typical properties of AG

$\begin{array}{ll}\text { Density } & 1.35 \mathrm{~g} / \mathrm{cm}^{3} \\ \text { Colour } & \text { White to yellow-beige } \\ \text { form } & \text { Sine powder } \\ \text { Stability } & \begin{array}{l}\text { Stable, not compatible with the } \\ \text { alcohols and the oxidizing agents. }\end{array} \\ \text { Water Solubility } & \begin{array}{l}\text { Water-soluble. An aqueous solution } \\ \text { is acidic to the litmus. }\end{array}\end{array}$

The XRF analysis was performed for obtaining the chemical composition of the Arabic gum was used in this work, the results shown in table 2

Table 2. Chemical composition of Arabic

\begin{tabular}{rr}
\hline Element & Concentration $\mathrm{m} / \mathrm{m} \%$ \\
\hline $\mathrm{MgO}$ & 0.017 \\
$\mathrm{Al}_{2} \mathrm{O}_{3}$ & 0.241 \\
$\mathrm{P}_{2} \mathrm{O}_{5}$ & 0.116 \\
$\mathrm{~K}_{2} \mathrm{O}$ & 0.025 \\
$\mathrm{CaO}$ & 1.142 \\
$\mathrm{TiO}_{2}$ & 4.032 \\
$\mathrm{MnO}$ & 0.028 \\
\end{tabular}




$\begin{array}{rr}\mathrm{Fe}_{2} \mathrm{O}_{3} & 0.068 \\ \mathrm{Cl} & 0.0436 \\ \mathrm{Ba} & 0.0339 \\ \mathrm{Cu} & 0.0053 \\ \mathrm{~Pb} & 0.0137 \\ \mathrm{Zn} & 0.0084\end{array}$

\section{Mixtures}

mixtures were produced as 6mixturegroups, each one of those groups consists of 6 cubic samples $(50 \mathrm{~mm} * 50 \mathrm{~mm} * 50 \mathrm{~mm})$ for compressive strength test and 6 prism samples (100mm*2.5mm*2.5mm) for flexural strength test, First group $\mathrm{G}_{0}$ mixtures were Prepared as a reference group only contain sand, cement, and water. Groups $\mathrm{G}_{1} \quad, \mathrm{G}_{2}, \mathrm{G}_{3}, \mathrm{G}_{4}, \mathrm{G}_{5}$ represent $0.1 \%, 0.3 \%, 0.5 \%, 0.7 \%, 0.9 \%$ respectively (ratio of AG to cement).For each one of the mixtures, the ratio of the sand to the cement was maintained at (2:1), and water to cement ratio was kept at (0.5). Table3 presents the mixture proportions.

Table 3. The proportions of the mixtures

\begin{tabular}{|c|c|c|c|c|}
\hline Sample & Cement \% & AG\% & $\begin{array}{l}\text { Water to } \\
\text { cement } \\
\text { ratio }\end{array}$ & $\begin{array}{l}\text { Sand to } \\
\text { cement } \\
\text { ratio }\end{array}$ \\
\hline$\overline{\mathrm{G}_{0}}$ & 100 & 00 & 00.5 & $2: 1$ \\
\hline $\mathrm{G}_{1}$ & 99.9 & 00.1 & 00.5 & $2: 1$ \\
\hline $\mathrm{G}_{2}$ & 99.7 & 00.3 & 00.5 & $2: 1$ \\
\hline $\mathrm{G}_{3}$ & 99.5 & 00.5 & 00.5 & $2: 1$ \\
\hline $\mathrm{G}_{4}$ & 99.3 & 00.7 & 00.5 & $2: 1$ \\
\hline $\mathrm{G}_{5}$ & 99.1 & 00.9 & 00.5 & $2: 1$ \\
\hline
\end{tabular}

\section{Preparation of test specimens}

After the weighing of elements with $0.01 \mathrm{gm}$ sensitive digital balance, Arabic gumdry mixing with the cement for the $G_{1}, G 2, G 3, G 4$, G5 for obtaining homogenous binder, binder andSand are mixed for approximately 2 minutesby hand, water wasadded to the mixer and then mixed for four minutes according toASTM C305 [11] after that it was poured into clean oiled moulds, the densification of thesamples wascarried out on a vibrating table in two layers, and eachlayerwas vibrated for (1min to $1.5 \mathrm{~min}$ ) until there aren't any bubbles that emerge to the surface of thecasting. The surface finish of thesampleswasperformedwith the use of spatula.Moulds were covered with plastic sheets to preserve the moisture and those samples werekept in the labat room temperature, for 24hours, ultimately, those samples were demoulded and cured in water, in which they wereuntil the testing time.

\section{Tests:}

\subsection{TheTest of the Compressive Strength:}

The test which is related to mortar's compressive strength wasconductedbased on (ASTM: C10902) [12]. Compressive strengths for each mixturewerecharacterized from the average of three cubic samples $(50 \times 50 \times 50) \mathrm{mm}$ were tested at 7 days of age (i.e. in early age) and 28 days (i.e. the standard age) following curing.

\subsection{Flexural strength Test:}

Based on the (ASTM C-293) [13] test approach wasperformed. A rectangular cross-sectionblock of dimensions $(100 \times 25 \times 25 \mathrm{~mm})$ is restingupon a pair of the supports and was loaded with the use of a loading nose which is in the middle of the distance between the support (1 point load).Flexuralstrength for each mixturewasidentified from a mean value ofthree prismspecimensthatwere tested at seven days of age and 28 days (i.e. the standard age) following curing.

\subsection{Workability:}

Workabilitytest was estimated based on Flow Table Test of Hydraulic Cement ASTM C230[14], also the mortar poured at 2 layers, each of them approximately with a thickness of $25 \mathrm{~mm}$ 
in a mould and tamp 20 times with the tamper, also the tamping pressure must be adequate for obtaining uniform mass in the mould, then pour the second layer in a similar process for the layer, after that cutoff mortar for obtaining plane surface flues with mould's top via drawing straightedge or towel's edge with sawing motion across mould's top. Following 1 minute from completing the pouring operation of mortar lift mould from the mortar. Right after that, the table isdropped 25 times in $15 \mathrm{sec}$, the mortar diameter ismeasuredalong 4 lines, and every one of the diameters isrecorded to the nearest millimeters.

\subsection{SEM analysis:}

Small specimens from the crushed samples in mechanical tests(flexural andcompressive strength tests) were used in the SEM analysis.

\section{Result and Discussions:}

The compressive strength testresults representthe average results of 3 samples for each replacement ratio. These results are shown in figure 1 .

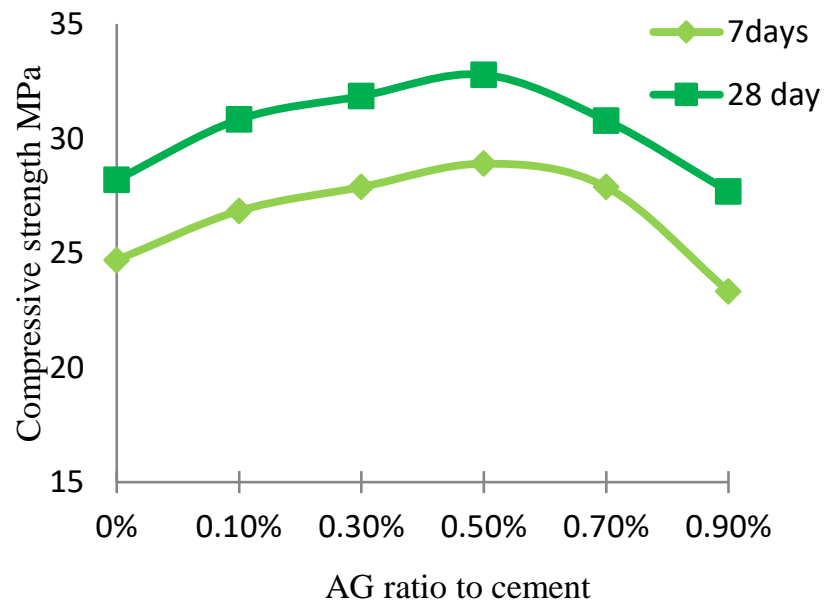

Figure 1.Results of compressive strength

From figure 1, it can be determined that for the early age and the standard age mixtures $\left(\mathrm{G}_{1}, \mathrm{G}_{2}\right.$, $\mathrm{G}_{3}$, and $\mathrm{G}_{4}$ ) have a compressive strength which is greater than the compressive strength of the control mix $\left(\mathrm{G}_{0}\right)$, the compressive strength gradually increases with an increase of $\mathrm{AG}$ ratio until reaches $G_{3}$ after that there was a decrease in the value of the compressive strength with the increase in the $A G$ ratio at $\left(\mathrm{G}_{4}\right.$ and $\left.\mathrm{G}_{5}\right)$, at $\mathrm{G}_{5}$ the compressive strength becomes lower than that at G1. For early and standard ages, the maximum Values of compressive strength are $28.9 \mathrm{MPa}$ and 32.78Mpa for $\mathrm{G}_{3}$ mixturewhich is $(0.5 \% \mathrm{AG})$ for 7 and 28 days respectively. Thepercentage of Enhancement in compressive strength reached approximately $17 \%$ at an early age and $16 \%$ at the standard age. The compressive strength value increases because of viscosity modifying the effect of AG that leads to improving the stability and cohesion of the microstructure of mortar[3] [7]. The decreased in compressive strength value following the $\mathrm{G}_{3}$ for the standard as well as the early ages because of increasing the $\mathrm{AG}$ ratio to cement higher than $0.5 \%$ cause disserve $\mathrm{C}_{3} \mathrm{~S}$ hydration and that lead to delaying $\mathrm{C}_{3} \mathrm{~S}$ and $\mathrm{C}_{3}$ Areaction as a result of water retention effect of AG [6], the overdosage of AG may because segregation that has a direct effect on cohesive and uniformity of mortar. The Flexural strength test results for all samples shown in figure 2 .

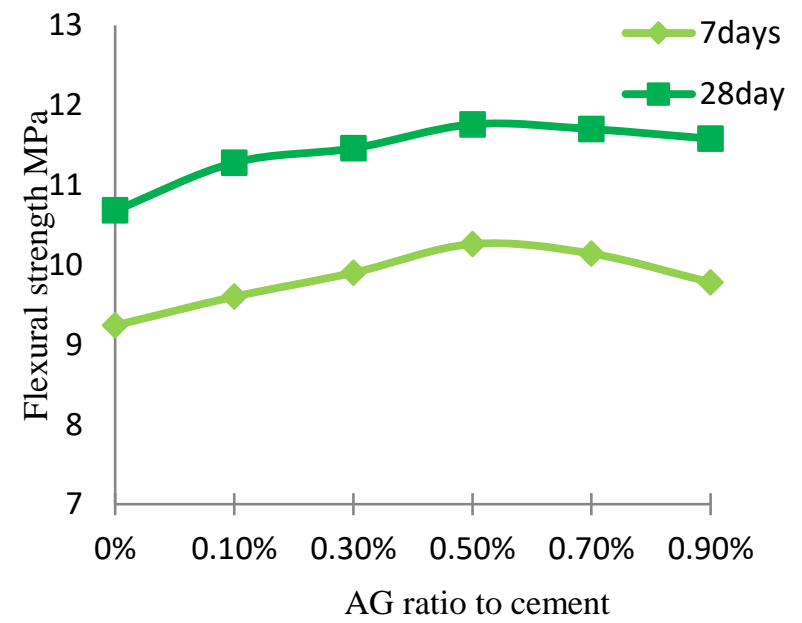

Figure 2. The results of the Flexural strength

From this figure it may be determined that for the standard age and the early age, the mixtures $\left(\mathrm{G}_{1}\right.$, $G_{2}, G_{3}, G_{4}$, and $G_{5}$ ) have flexural strength value which Is greater than the flexural strength value of the control mix $\left(\mathrm{G}_{0}\right)$, the strength gradually increase with the increase of $A G$ ratio until 
reaches $\mathrm{G}_{3}$ then at $\mathrm{G}_{4}$ and $\mathrm{G}_{5}$ the flexural strength decreased with the increase of AG ratio. For early and standard ages, $\mathrm{G}_{3}$ have a higher value where recorded $10.26 \mathrm{MPa}$ and $11.76 \mathrm{MPa}$ respectively for the early age and the standard age. The percentage of Enhancement of flexural strength increased by approximately $11 \%$ at an early age and just $10 \%$ for standard age. Increasing the flexural strength value was because of the viscosity modifying effect related to AG that lead to improving the stability and cohesion of the microstructure of mortar[3][7]. The decreased in flexural strength value after $\mathrm{G}_{3}$ for early age and the standard age due to increasing the $\mathrm{AG}$ ratio to cement higher than $0.5 \%$ cause disserve $\mathrm{C}_{3} \mathrm{~S}$ hydration and that lead to delaying the $\mathrm{C}_{3} \mathrm{~S}$ and $\mathrm{C}_{3} \mathrm{~A}$ reaction as a result of water retention effect of AG [6], the overdosage of AG may because segregation that has a direct effect on cohesive and uniformity of mortar the effect of $\mathrm{AG}$ on workability for all groups as compared with $G_{0}$ represented in figure(3)

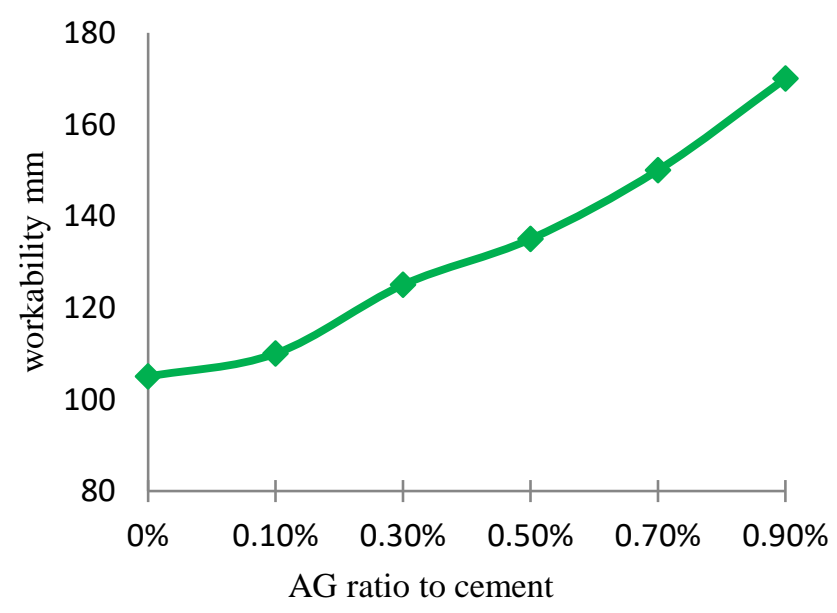

Figure 3. Effect of AG on workability

From this figure were observed that the increase in $\mathrm{AG}$ ratio increases the workability. Theincreasing in workability due to the presence of Soluble polysaccharides that caused increasing the water retention capacity as well as improving the workability [6]. The maximum value at $\mathrm{G}_{5}$ (Contain $0.9 \% \quad \mathrm{AG}$ ) higher than $\mathrm{G}_{0}$ by approximately $62 \%$.SEM analysis wasperformed for a sample from $\mathrm{G}_{3}$ (have the best results of mechanical tests as compared with other groups) and $\mathrm{G}_{0}$ (reference group). As indicated in figures $(4 a \& 4 b)$ for a standard sample of the $\left(\mathrm{G}_{0}\right)$ group, the micro-structure includes large crystals and it is possible to observe empty spacesandpores between crystals.

As can be seen in the figures ( $5 a$ and $5 b$ ) for the sample of $\mathrm{G}_{3}$, micro-structure is more homogeneous as compared with that of $\mathrm{G}_{0}$ where the crystals are finer and the pores disappeared, that may be as a result of the viscosity modifying effect of AGthat lead to spacing the cement particles from each other and form fine crystals that lead to filling the empty spaces and reduce the pores in the microstructure.

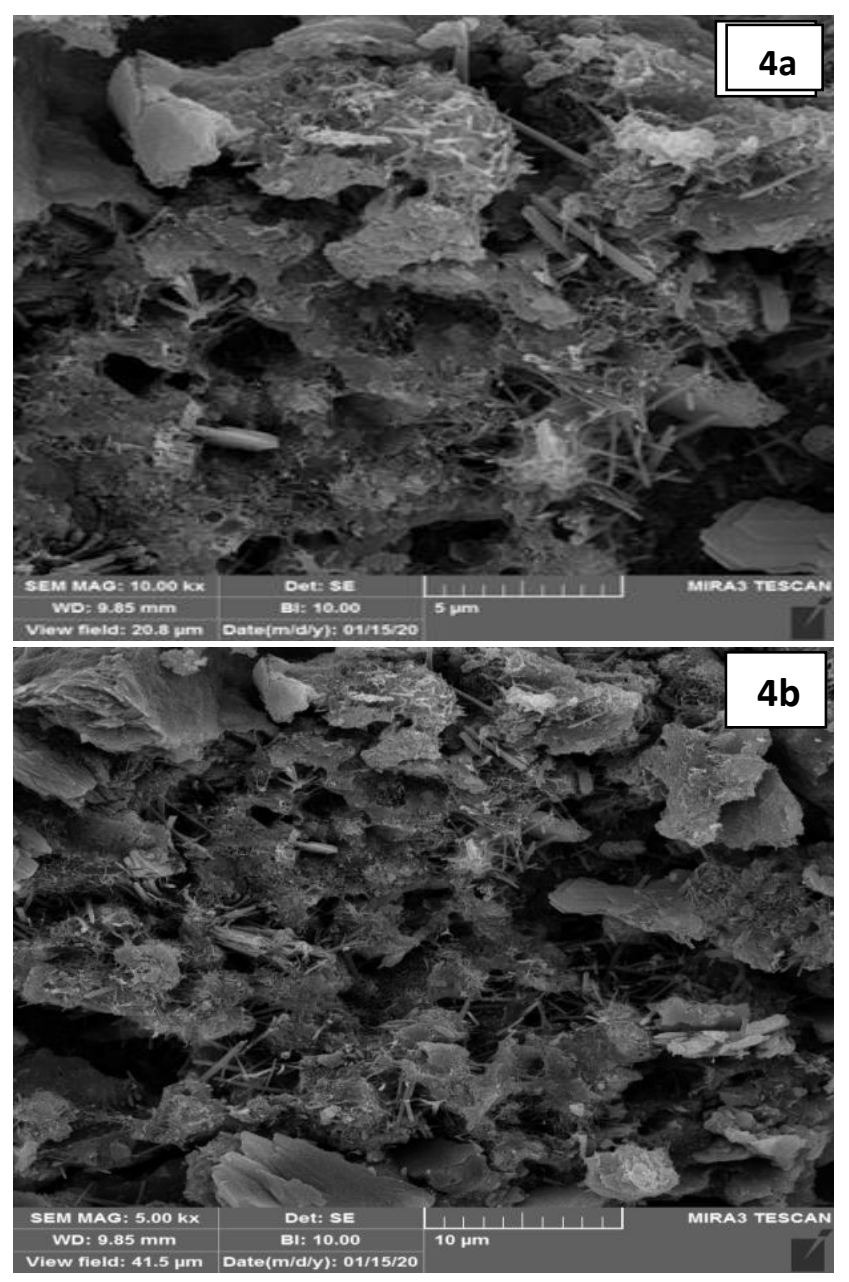

Figure $4 \mathbf{a}, \mathbf{4 b}$.the microstructure of standard sample of $\mathrm{G}_{0}$ 

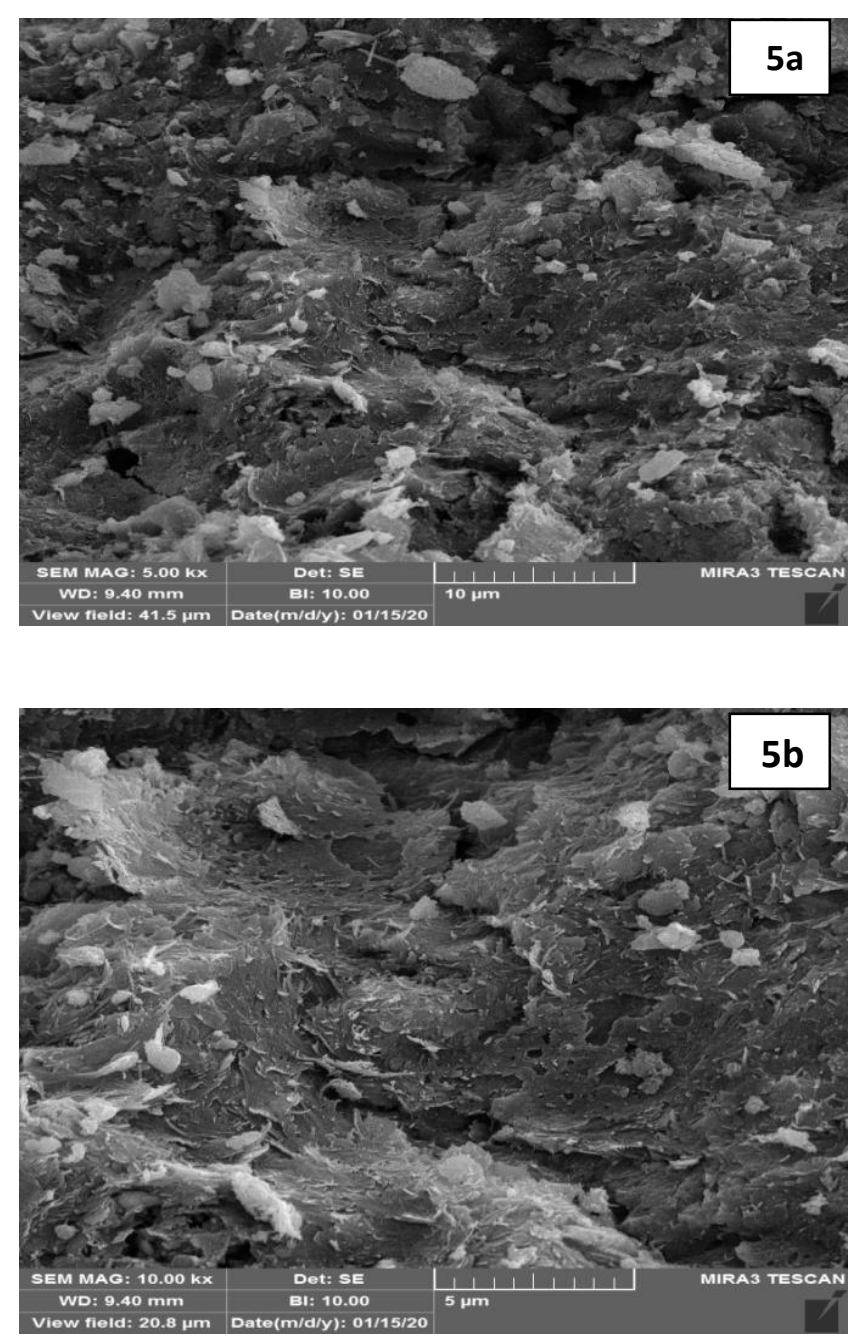

Figure 5a,5b.the microstructure of the sample of G3

\section{Conclusions}

Based onthe experimental results that are related to workability, flexural strength, as well as compressive strength it was indicated that using AG in ordinary cement mortar in suitable replacement ratio enhanced the flexural and compressive strengths and improved the mortar's workability, group $\mathrm{G}_{3}$ (contain $0.5 \% \mathrm{AG}$ ) was recorded as the optimal result in mechanical testsin comparison to other groups, the presence of AG in ordinary cement mortar increased the workability,from SEM analysis observed the effect of $\mathrm{AG}$ on forming more homogeneous microstructure in $\mathrm{G}_{3}$ in comparison to the microstructure related to $\mathrm{G}_{0}$.

\section{Conflict of interest}

The authors confirm that there's no conflict of interest.

\section{References}

1. A. M. Saleh,(2001) "High-Strength Concrete and the Resistance through the Improvement of Natural Additions," ed: International University of Civil Engineering, Moscow, Russia.

2. K. Karamalla, N. Siddig, and M. Osman,(1998) "Analytical data for Acacia Senegal var. Senegal gum samples collected between 1993 and 1995 from Sudan," Food hydrocolloids, vol. 12, pp. 373-378.

3. K. H. Khayat,(1998) "Viscosity-enhancing admixtures for cement-based materials - an overview," Cement and Concrete Composites, vol. 20, Issues 2-3, pp. 171-18.

4. C. Zhao, Q. Zhao, Y. Zhang, and M. Zhou, (2015)"The Effect of Gum Arabic on the Dispersion of Cement Pastes," in Proceedings of the 11th International Congress for Applied Mineralogy (ICAM), pp. 483-494.

5. P. Zakka, O. Job, and N. Anigbogu, (2015)"Ecological self-compacting concrete using Gum Arabic as a plasticizer," West Africa Built Environment Research (WABER), p. 10.

6. R. Mbugua, R. Salim, and J. Ndambuki, (2016)"Effect of Gum Arabic Karroo as a water-reducing admixture in cement mortar," Case Studies in Construction Materials, vol. 5, pp. 100-111.

7. A. U. Elinwa and M. Umar, 2017 "X-ray diffraction and microstructure studies of gum Arabic-cement concrete," Construction and Building Materials, vol. 156, pp. 632-638.

8. Iraqi Specification, No.5/1984,( 2001) "Portland cement" Central Organization for Standardization and Quality Control, Baghdad. 
9. Iraqi Specification, No.45/1984, (2001)“Aggregates from natural sources for concrete and construction", Central Organization for Standardization and Quality Control, Baghdad.

10. Islam, A. M., et al. (1997) "A review of recent developments on the regulatory, structural and functional aspects of gum Arabic." Food Hydrocolloids, vol.11.4, pp. 493-505.

11. ASTM C305, (2004)"Standard method of test for mechanical mixing of hydraulic cement pastes and mortars of plastic consistency".

12. ASTM C 109/ C 109M-02, "Standard Test Method for Compressive Strength of Hydraulic Cement mortars", (Using 2-in. or [50-mm] Cube Specimens).

13. ASTM C293 / C293M-16, Standard Test Method for Flexural Strength of Concrete (Using Simple Beam With Center-Point Loading), ASTM International, West Conshohocken, PA, 2016.

14. ASTM C 230/C 230M - 03(2003) Standard Specification for Flow Table for Use in Tests of Hydraulic Cement, December. 